\title{
Observed benevolence and hostility as determinants of interpersonal attraction
}

\begin{abstract}
JAY HEWITT and BETTY J. CHUNG, University of Victoria, Victoria, B.C., Canada
\end{abstract}

Females listened to a tape recording in which two women ( $A$ and $B$ ) gave their impression of one another. $A$ evaluated $B$ either favorably or unfavorably and then $B$ evaluated $A$ either favorably or unfavorably. The $S$ s were more attracted to $B$ when $B$ 's evaluation of $A$ was positive than when it was negative. The $S s$ showed a decrease in attraction to $B$ when $B$ 's evaluation of $A$ was negative, and this was especially marked when $A$ 's evaluation of $B$ was positive.

According to the reward theory of interpersonal attraction, the attraction of one person $(P)$ to another person $(0)$ is a function of the degree to which $\mathrm{O}$ rewards or reinforces P (Byrne \& Nelson, 1965; Homans, 1961; Thibaut \& Kelley, 1959). Griffitt $(1968,1969)$ and Lott $(1968)$ have extended this theory by suggesting that people are attracted to those with whom they expect or anticipate a rewarding interaction. If this is true, it might be possible for $P$ to develop a liking for $O$ merely by observing $O$. If $O$ were observed to act in a rewarding manner toward someone else, $P$ might infer that $O$ would be the type of person who would act in a rewarding manner toward him.

In the present experiment, Ss listened to a tape recording in which two people ( $A$ and $B$ ) evaluated one another. A's evaluation of $B$ was either positive or negative, and B's evaluation of $A$ was either positive or negative. According to the hypothesis put forth above, Ss should be more attracted to $B$ when B's evaluation of A is positive than when it is negative. Judgments about $B$ should also be affected by the context in which B's actions occur (Davis \& Jones, 1965). Person B may be seen as a very benevolent person if he says good things about someone who has previously evaluated him negatively. Conversely, B may be seen as a very hostile person if he derogates someone who evaluated him positively. In either case, there should be more attraction to B when A's evaluation of $B$ is negative than when it is positive.

$$
\text { METHOD }
$$

Forty-two female Ss listened to a tape recording in which an $E$ asked two female confederates ( $A$ and $B$ ) a series of questions. Person B was asked to describe her in terests, goals in life, and personal problems, and then Person $A$ was asked to give her impression of B. Next, Person A was asked to describe her interests, goals in life, and personal problems, and then Person B was asked to give her impression of $A$. Person A's impression of $B$ was either generally positive ("good natured, interesting, understanding, overcritical, and warm") or negative ("intelligent, cold, insincere, offensive, and shallow'), and Person B's impression of A was either generally positive ("kind, sincere, imaginative, overcritical, and mature") or negative ("intelligent, deceitful, neurotic, unpleasant, and untrustworthy"). The Ss were asked to rate their attraction to $B$ after $B$ 's self-description and again at the end of the tape (after A and B had evaluated one another). Both ratings were made on a 21 -point scale, ranging in value from +10 (like very much) to -10 (dislike very much).

\section{RESULTS AND DISCUSSION}

There appeared to be some difference among the four groups in terms of their initial attraction to B. To control for these differences, a two-way analysis of covariance was carried out on the data. As predicted, there was greater attraction to $B$ when B's evaluation of $A$ was positive than when it was negative $(F=26.10, \mathrm{df}=1 / 37$, $p<.001)$. This was true regardless of

Table 1

Mean Attraction to $\mathrm{B}$

\begin{tabular}{llcccr}
$\begin{array}{c}\text { B's Evaluation } \\
\text { of A }\end{array}$ & $\begin{array}{c}\text { A's Evaluation } \\
\text { of B }\end{array}$ & $\mathrm{N}$ & Initial & $\begin{array}{c}\text { Attraction } \\
\text { Final }\end{array}$ \\
\hline \multirow{2}{*}{ Positive } & Negative & 10 & 3.60 & 4.40 & +0.80 \\
& Positive & 10 & 3.20 & 3.10 & -0.10 \\
Negative & Negative & 11 & 5.91 & 1.36 & -4.55 \\
& Positive & 11 & 4.64 & -3.82 & -8.46 \\
\hline
\end{tabular}

whether $A$ 's evaluation of $B$ was positive $(t=5.01, \mathrm{df}=37, \mathrm{p}<.001)$ or negative $(t=2.92, d f=37, p<.01)$. The latter result is especially interesting, for it suggests that people may be more attracted to someone who fails to retaliate than to someone who actually does re taliate.

It was initially predicted that there would be more attraction to Person $B$ when $A$ 's evaluation of $B$ was negative than when it was positive. Inspection of the data suggests that there was practically no effect of A's evaluation when B's evaluation was positive (although the means were in the predicted direction). The hypothesis was confirmed, however, when B's evaluation of $A$ was negative $(\mathrm{t}=3.76, \mathrm{df}=37, \mathrm{p}<.001)$. When one person is observed to act in an unfriendly manner toward a second person, people may be less hostile toward the first person when there are extenuating circumstances (the second person has previously acted in an unfriendly manner toward the first person) than when there is apparently no justification for the observed hostility (when the second person has previously acted in a friendly manner toward the first person). The means are presented in Table 1 .

As can be seen from Table 1 , there was a sizeable decrease in attraction to B when B's evaluation of $A$ was negative (mean decrease $=6.50$ ). It is primarily on the basis of these data that a reformulation of reward theory would appear to be necessary. Reward theory predicts that people should dislike those who treat them in an unfriendly manner. Merely observing one person act in an unfriendly manner toward someone else is apparently sufficient to create a dislike, and merely observing the context in which these actions occur is apparently sufficient to alter the magnitude of the dislike.

\section{REFERENCES}

BYRNE, D., \& NELSON, D. Attraction as a linear function of proportion of positive reinforcements. Joumal of Personality \& Social Psychology, 1965, 1, 659-663.

GRIFFITT, W. Anticipated reinforcement and attraction. Psychonomic Science, 1968, 11 . 355.

GRIFFITT, W. Attitude evoked anticipatory responses and attraction. Psychonomic Science, $1969,14,153$.

HOMANS, G. Social behavior: Its elementary forms New York: Harcourt, Brace \& World, 1961.

JONES, E. E., \& DAVIS, K. E. From acts to dispositions: The attribution process in person perception. In L. Berkowitz (Ed.), Advances in experimental sacial psychology. Vol. 2. New York: Academic Press, 1965. Pp. 219-266.

LOTT, A. J., \& LOTT, B. E. A learning theory approach to interpersonal attitudes. In $A$. G. Greenwald. T. C. Brock, and T. M. Ostrom (Eds.), Psycholagical foundations of attitudes. New York: Academic Press, 1968.

THIBAUT, J., \& KELLEY. H. H. The social psychology of groups. New York: Wiley, 1959. 